OPEN ACCESS

Edited by:

Lifeng Zhu,

Nanjing Normal University, China

Reviewed by:

Bing Tian,

Zhejiang University, China

Andreas Schramm,

Aarhus University, Denmark

*Correspondence:

Huaiping Zheng

hpzheng@stu.edu.cn

Specialty section: This article was submitted to

Microbial Symbioses,

a section of the journal

Frontiers in Microbiology

Received: 27 June 2019 Accepted: 09 January 2020 Published: 07 February 2020

Citation:

Liu H, Tan KS, Zhang X, Zhang H, Cheng D, Ting Y, Li S, Ma H and Zheng $H$ (2020) Comparison of Gut Microbiota Between Golden and Brown Noble Scallop Chlamys nobilis and Its Association With Carotenoids. Front. Microbiol. 11:36. doi: 10.3389/fmicb.2020.00036

\section{Comparison of Gut Microbiota Between Golden and Brown Noble Scallop Chlamys nobilis and Its Association With Carotenoids}

\author{
Hongxing Liu 1,2,3, Kar Soon Tan 1,2,3, Xinxu Zhang ${ }^{4}$, Hongkuan Zhang 1,2,3, Dewei Cheng ${ }^{1,2,3}$, \\ Ye Ting ${ }^{1,2,3}$, Shengkang $\mathrm{Li}^{1,2,3}$, Hongyu $\mathrm{Ma}^{1,2,3}$ and Huaiping Zheng ${ }^{1,2,3 *}$ \\ ${ }^{1}$ Key Laboratory of Marine Biotechnology of Guangdong Province, Institute of Marine Sciences, Shantou University, \\ Shantou, China, ${ }^{2}$ Mariculture Research Center for Subtropical Shellfish \& Algae of Guangdong Province, Shantou, China, \\ ${ }^{3}$ STU-UMT Joint Shellfish Research Laboratory, Shantou University, Shantou, China, ${ }^{4}$ Institute for Advanced Study, \\ Shenzhen University, Shenzhen, China
}

Many marine bivalves are regarded as healthy foods due to their high carotenoid content. Only plants and microorganisms have natural carotenoids biosynthesis ability, hence, animals such as bivalves must obtain carotenoids from their diets. Due to the filter-feeding behavior of bivalves, they have high diversity of gut microbes. However, the relationship between gut microbes and carotenoids has not been explored in mollusks. In the present study, the interaction between gut microbes and carotenoids in two polymorphic noble scallop Chlamys nobilis, golden scallops (designated GG) and brown scallops (designated BW), were studied. The gut of GG and BW showed statistically different bacteria communities. Results from 16S rRNA gene sequencing and qPCR analysis revealed that the gut of GG had significantly higher relative abundance of carotenoids-producing bacteria Brevundimonas, compared with BW. Moreover, HPLCMS analysis showed that isolate Brevundimonas could produce astaxanthin. The current findings are very useful as they could form the basis for future studies in determining the relationship between gut microbiota and carotenoids absorption in bivalves.

Keywords: scallop, Chlamys nobilis, carotenoids, gut microbe, Brevundimonas, bacterial abundance

\section{INTRODUCTION}

Gut microbiota is regarded as an integral component of the host because of its important role in host digestion and health (Sommer and Bäckhed, 2013; Sonnenburg and Bäckhed, 2016). Studies in humans and other vertebrates have revealed that gut microbiota produces many metabolites, including short-chain fatty acids (Immerseel et al., 2010), essential vitamins and amino acids (Ikeda et al., 1979; Ramotar et al., 1984; Lozupone et al., 2012; Mardinoglu et al., 2015), as well as some digestive enzymes (Yolton and Savage, 1976; Dabek et al., 2008; Carmody and Turnbaugh, 2014) that are beneficial to the host. The microbiomes of terrestrial invertebrates, especially insects such as wasps (Adams et al., 2011), flies (Erkosar et al., 2013), termites (Poulsen et al., 2014), and beetles (Salem et al., 2017), have been studied and shown to be involved in host nutrient acquisition provided by symbiotic bacteria. On the other hand, in marine invertebrates, such as mollusks (Trabal et al., 2014), crustaceans (Givens et al., 2013) and sponges (Richardson et al., 2012; 
Schmitt et al., 2012), microbiome studies have mostly focused on the dynamics of bacterial communities under various nutrients and environmental conditions. A growing number of studies have shown that symbiotic bacteria provide carotenoids to many invertebrates, as in the accessory nidamental glands (ANG)-bacterial community in squids (Barbieri et al., 1996; Grigioni et al., 2000) and endosymbiotic bacteria in whiteflies (Sloan and Moran, 2011).

Carotenoids are lipid-soluble tetraterpenoid compounds biosynthesized by plants and microorganisms (algae, bacteria, and fungi). In general, animals cannot biosynthesize carotenoids and must, therefore, obtain them from their diets (Tanumihardjo, 2013). However, in recent years, some insects such as aphids (Moran and Jarvik, 2010; Nováková and Moran, 2011), gall midges (Cobbs et al., 2013), and spider mites (Altincicek et al., 2012) have been found to be able to synthesize their own carotenoids by trans-kingdom transfer genes from fungi. As important antioxidants, carotenoids play many important functions in human and animal health (Tanumihardjo, 2013). Moreover, as natural pigments (with color ranging from yellow to red), carotenoids are also involved in the body coloration of animals (Maoka, 2009), and have been reported in vertebrates such as fish (Wang et al., 2006), frogs (Umbers et al., 2016), and birds (Negro and Garrido-Fernèndez, 2000; Weaver et al., 2018), as well as invertebrates such as silkworm Bombyx mori (Tabunoki et al., 2004), sea urchin Strongylocentrotus intermedius (Borisovets et al., 2002) and turban shell Turbo cornutus (Maoka, 2011).

In mollusks, which are the second largest phylum in the animal kingdom, some groups including Polyplacophora, Gastropods, Bivalves, and Cephalopods are rich in carotenoids ranging from 10 to $140 \mu \mathrm{g} / 100 \mathrm{~g}$ (Matsuno and Hirao, 1989), albeit varying in different tissues (Kantha, 1989). Moreover, mollusks contain a wide range of carotenoids such as $\beta$-carotene, lutein, zeaxanthin, diatoxanthin, and astaxanthin, which is mainly obtained from microalgae, with some metabolically modified into other carotenoid forms (Matsuno, 2001). Some mollusks are therefore important sources of carotenoids for humans.

The noble scallop Chlamys nobilis is a marine bivalve, which is very popular in China, and naturally distributed in Vietnam, China, and Japan. Noble scallops display polymorphism in their shell colors (i.e., golden, purple, yellow, brown, and white) and muscles color (golden or white). Our previous studies have shown that the golden scallops, which have golden shells and adductor, are very rich in total carotenoid content compared with brown scallops with brown shells and white adductors (Zheng et al., 2010). The SRB-like-3 gene is believed to be involved in the accumulation of carotenoids in golden scallops (Liu et al., 2015). Intriguingly, we also observed that golden scallops have a golden gut, while brown scallops have a white gut. Therefore, we wondered whether the golden gut of golden scallops had a higher carotenoid content than white guts and, if so, whether there could be some specific gut bacteria associated with this pigmentation and carotenoid content.

In the present study, two noble scallops C. nobilis from the same breeding stock. i.e., golden scallops (with golden shells and golden gut, designated GG) and brown scallops (with brown shells and white gut, designated BW), were used. The total carotenoids content (TCC) in the adductor, hemolymph, and gut were compared, while the bacterial 16S rRNA genes in the gut were sequenced and analyzed. Finally, some carotenoidsproducing bacteria were isolated by culture-based methods and identified using high performance liquid chromatography-mass spectrometry (HPLC-MS).

\section{MATERIALS AND METHODS}

\section{Experimental Materials and Sample Collection}

Golden and brown noble scallop strains originating from the same family with the same parents, established using the artificial breeding method previously described by Zheng et al. (2013), were cultured under the same conditions from D-shape larvae to adults at Shen'ao Bay $\left(23^{\circ} 29^{\prime} \mathrm{N}, 117^{\circ} 07^{\prime} \mathrm{E}\right)$ of Guangdong Province, China. One hundred individuals of 1-year-old adult female scallops (50 golden and 50 brown individuals) were randomly selected from the two strains for this experiment (Figure 1). After cleaning, individual scallops were measured, i.e., shell length with a vernier caliper to the nearest $0.1 \mathrm{~mm}$ and weighed on a digital balance to the nearest $0.1 \mathrm{~g}$. The scallops were then placed in two $500 \mathrm{~L}$ polyethylene tanks for 1 week for acclimation to laboratory conditions. Each scallop was fed daily with $4 \times 10^{6}$ cells of Nitzschia closterium. The seawater temperature was $23.6^{\circ} \mathrm{C}$ and salinity $31.1 \mathrm{psu}$, with water changed daily.

Five scallops of approximately the same size (the same shell length) were randomly selected from each tank. The outer surface of each scallop's gut was washed thoroughly with sterile water and disinfected with $75 \%$ ethanol before being dissected. Next, each gut was placed into a sterile tube, and fully homogenized with $1 \mathrm{~mL}$ sterile sea water using a sterile plastic pestle. Samples were then placed into two eppendorf tubes, for bacterial DNA extraction and to isolate bacteria for culture. The gut, adductor and hemolymph of five other scallops from each tank were sampled according to the method described previous (Zheng et al., 2012a) for TCC determination. All samples were stored in liquid nitrogen until processing, except the gut samples used for bacteria isolation.

\section{Determination of Total Carotenoids Content (TCC)}

Total carotenoids content was determined as described previously (Zheng et al., 2010). Briefly, the adductor, gut and hemolymph samples were freeze-dried in a vacuum pump (ScanVac CoolSafe, LaboGene, Denmark) for $48 \mathrm{~h}$, and ground to homogenous powder in a mortar. Next, $0.02 \mathrm{~g}$ of each sample was mixed with $1 \mathrm{~mL}$ acetone with shaking $(200 \mathrm{rpm})$ for $1 \mathrm{~h}$ at $25^{\circ} \mathrm{C}$ in the dark. The extract was centrifuged at $5000 \mathrm{rpm}$ for $5 \mathrm{~min}$. The supernatant was measured with a spectrophotometer (UV2501PC, SHIMADZU, Japan) from 400 to $700 \mathrm{~nm}$ wave length. The TCC ( $\mu \mathrm{g} / \mathrm{g}$ dry weight) was calculated by using the 


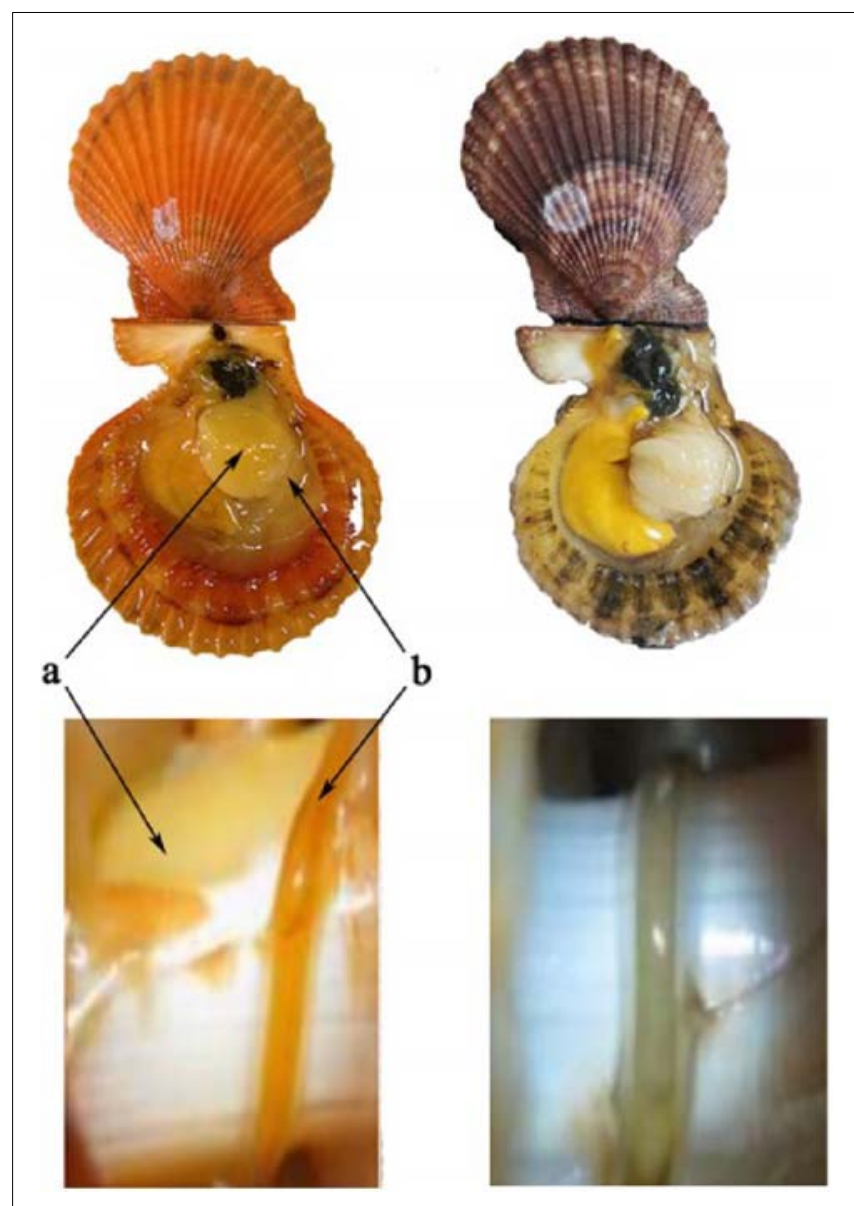

FIGURE 1 | Golden and brown noble scallops and their guts. The golden scallop with golden shell, golden adductor and golden gut (left, named as $\mathrm{GG}$ ), and the brown scallop with orange shell, white adductor and white gut (right, named as BW). Two kinds of tissues: adductor (a) and gut (b).

extinction coefficient $\mathrm{E}(1 \%, 1 \mathrm{~cm})$ of 1.900 at the absorption value of $480 \mathrm{~nm}$ (Yanar et al., 2004).

\section{DNA Extraction, PCR Amplification and Illumina Sequencing}

The gut bacterial DNA was extracted using the QIAamp DNA stool kit (Qiagen) following the manufacturer's instructions, and the concentration and quality of the DNA determined at A260 and A280 nm using an ND-1000 spectrophotometer (NanoDrop Technologies, Wilmington, DE, United States) and 1\% agarose gel electrophoresis with Gel Red ${ }^{\mathrm{TM}}$ staining. The bacterial $16 \mathrm{~S}$ rRNA gene was amplified by PCR (Caporaso et al., 2011) using the primers 515F (5'-GTGCCAGCMGCCGCGG-3') and 806R ( $5^{\prime}$-GGACTACHVGGGTWTCTAAT-3'), which target the hypervariable V4 region of the $16 \mathrm{~S}$ rRNA gene. Unique eightbase barcodes were added to each primer to distinguish the PCR products. The PCR product was gel purified using the QIAquick Gel Extraction Kit (Qiagen, Germany), and $30 \mathrm{ng}$ of each purified PCR product was subjected to sequencing using the Illumina HiSeq 2000 platform (Total Genomics Solution
Institute, Shenzhen, China). Raw reads containing a 50 bp continuous fragment or with an average quality score less than 30 and/or any ambiguities were removed. Reads containing more than two mismatches to the primers or more than one mismatch to the barcode were discarded. Filtered reads were then merged by overlapping paired-end reads using FLASH (Version1.2.7) with an overlap length of more than $15 \mathrm{bp}$.

\section{Microbial Community Compositions and Their Potential Functions}

Operational Taxonomic Units (OTUs) were classified using USEARCH (v7.0.1090) (Wang et al., 2007) at a 97\% similarity level. The taxonomy assignment of each $16 \mathrm{~S}$ rRNA gene sequence was analyzed by the RDP Classifier ${ }^{1}$ using assign_taxonomy.py in QIIME. The relative abundance of each OTU was examined at different taxonomic levels. Alpha diversity indices (Shannon and Chao 1) were calculated by alpha_diversity.py in QIIME. Alpha diversity indices were compared among two groups with a nonparametric t-test (Monte Carlo, 999 permutations) in QIIME (Schloss et al., 2009). The principal coordinate analysis (PCoA) based on weighted UniFrac distance matrix was performed in QIIME. Heatmap and Venn diagrams of gut microbiota were generated from the $\mathrm{R}$ project for statistical computing ${ }^{2}$ To explore the potential functions of the bacterial communities, the PICRUSt (Phylogenetic Investigation of Communities by Reconstruction of Unobserved States) was used to predict the metabolic pathways in the gut of each sample (Langille et al., 2013). OTUs data were mapped to the Greengenes database and $81 \%$ of genes were classified to a Tier 1 KEGG orthology (KO) function. The nearest sequenced taxon index (NSTI) scores averaged $0.053 \pm 0.012$, indicating a relatively good match to reference genomes (ideal NSTI $\leq 0.03$ ). Sequenced data has been deposited at NCBI under Bioproject number PRJNA574069.

\section{Isolation of Carotenoid-Producing Bacteria}

Three solid media [Nutrient agar, Luria-Bertani (LB) agar, and Marine agar 2216] were used to isolate carotenoid-producing bacteria (Asker et al., 2007). The gut samples of GG $(n=5)$ were used as the source of bacteria. Samples were homogenized with sterile sea water using a sterile plastic pestle. Next, $0.2 \mathrm{ml}$ of a 10 fold dilution of each sample was spread on LB solid medium in duplicate, and the plates incubated at room temperature.

After incubation for $48 \mathrm{~h}$, yellow-, orange-, or red-colored bacterial colonies were isolated and identified by $16 \mathrm{~S}$ rRNA genebased analysis using the universal bacterial primers $27 \mathrm{~F}$ and 1492R (Lane, 1991). Isolates that shared 99\% or higher $16 \mathrm{~S}$ rRNA gene sequence similarity were considered as the same species. To identify carotenoid-producing bacteria, the carotenoids of bacterial cells were extracted by organic solvent (acetone). The absorbance of the extract was assessed at $\lambda$ between 260 and $700 \mathrm{~nm}$ at room temperature by using a spectrophotometer (BioTek, United States). The potential carotenoid producing

\footnotetext{
${ }^{1}$ http://rdp.cme.msu.edu/

${ }^{2}$ http://www.r-project.org/
} 
TABLE 1 | Primer utilized for gene analysis.

\begin{tabular}{|c|c|c|c|}
\hline Primer name & Sequence $\left(5^{\prime}-3^{\prime}\right)$ & Application & References \\
\hline 16S-QF & ACTCCTACGGGAGGCAGCAG & qPCR of V4 hypervariable region of bacterial $16 \mathrm{~S}$ rRNA gene & Guo et al., 2008 \\
\hline 16S-QR & ATTACCGCGGCTGCTGG & & \\
\hline$\beta$-actinF & CAAACAGCAGCCTCCTCGTCAT & qPCR of host $\beta$-actin gene & Zheng et al., 2012b \\
\hline$\beta$-actinR & CTGGGCACCTGAACCTTCGTT & & \\
\hline $16 \mathrm{~S}-27 \mathrm{~F}$ & AGAGTITGATCCTGGCTCAG & PCR of bacterial $16 S$ rRNA gene & Lane, 1991 \\
\hline 16S-1492R & GGTTACCTTGTACGACTT & & \\
\hline Bre-QF & GCCTTCGCCACTGGTGTTCTTCC & qPCR of V4-V5 hypervariable region of Brevundimonas 16S rRNA gene & This study \\
\hline Bre-QR & TGCCTITGATACTGGGTGTCTTG & & \\
\hline
\end{tabular}

bacteria are currently preserved in our laboratory at Shantou University. Further identification of bacterial carotenoids was carried out using HPLC-MS system (Agilent 1100, United States) according to the method described by Asker et al. (2007). Astaxanthin (Sigma, St. Louis, MO, United States) was used as an external standard.

\section{Quantitative PCR}

Quantitative PCR was performed to quantify the abundance of $16 \mathrm{~S}$ rRNA gene in gut samples of scallops. Total gut bacteria were quantified by real-time PCR using the 16S RNA gene-specific primers (Guo et al., 2008). Species specific real-time PCR were applied to quantify the Brevundimonas $16 \mathrm{~S}$ rRNA gene located in the V4-V5 hypervariable region and normalized by real-time PCR data of the host $\beta$-actin gene (Table 1). The quantitative realtime PCR was performed on an ABI 7300 Real-Time Detection System (Applied Biosystems, United States) using the SYBR Premix Ex Taq II qRT-PCR Kit (TaKaRa). PCR cycle threshold (Ct) values and standard curve were obtained by amplifying 10fold serially diluted plasmids. Each amplification efficiency was also determined.

\section{Statistical Analysis}

Total carotenoids content, relative abundance of bacterial genera and relative abundance of functional gene are expressed as mean \pm standard deviation of the mean (SD).

The abundance of bacterial genera and functional gene with statistically significant difference were assessed using Metastats (White et al., 2009). Metastats data were then evaluated using the non-parametric Kruskal-Wallis test with false discovery rate (FDR) correction for multiple testing and significance for all analyses was set at $P<0.05$ unless noted otherwise.

\section{RESULTS}

\section{Comparison of Total Carotenoids Content (TCC) in Tissues of Scallops}

The TCC from three tissues of golden and brown scallops is shown in Figure 2. In all tested tissues, GG had significantly higher TCC compared with BW $(P<0.05)$. Gut had the highest TCC among the three tissues tested.

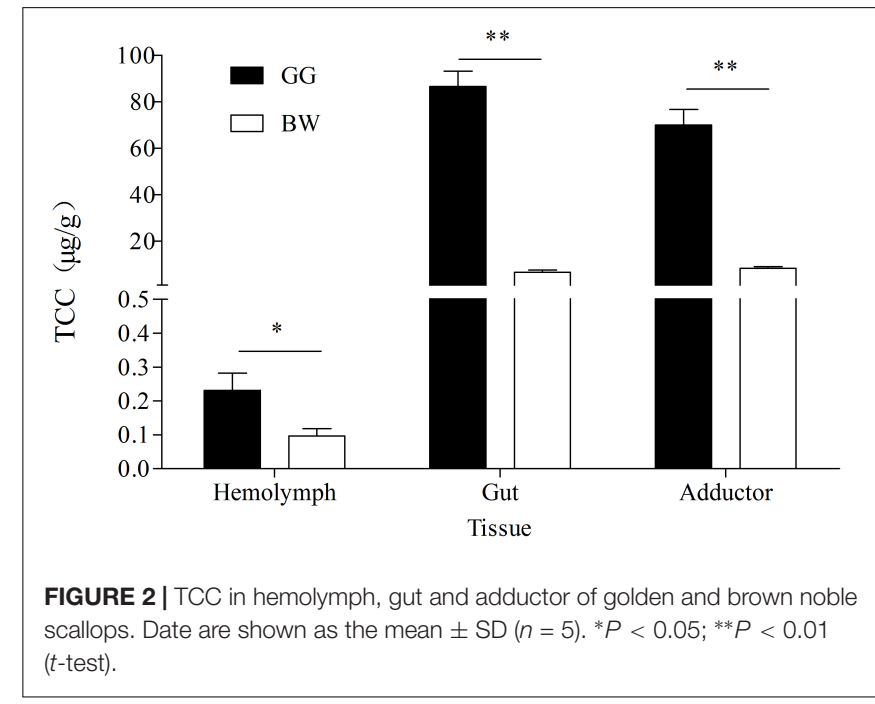

\section{Comparison of Gut Bacterial Diversity Between Golden and Brown Scallops}

After filtering out low quality reads, a total of 365360 reads of the V4 region of the $16 \mathrm{~S}$ rRNA genes were obtained from 10 samples. Reads were clustered into OTUs at a $97 \%$ similarity level, in which each OTU represented a unique phenotype. A total of 1862 unique OTUs were obtained from gut bacterial community. Over 54\% of all OTUs were shared by the gut of the two scallops, with GG having more unique OTUs compared with BW (data no shown).

\section{Comparison of Gut Bacterial Composition Between Golden and Brown Scallops}

The bacterial profiles of the 10 samples analyzed generated 37 distinctive bacterial phyla. Both GG and BW had similar gut bacterial composition at the phylum level. The dominant phyla include Proteobacteria (39.3\% 84.1\%), Tenericutes $(3.4 \% \sim 19.9 \%)$, Bacteroidetes $(7.1 \% \sim 32.6 \%)$, Firmicutes $(0.4 \% \sim 18.9 \%)$, Fusobacteria $(0.2 \% \sim 10.0 \%)$, and Actinobacteria $(0.1 \% \sim 1.5 \%)$, which accounted for $86.78-98.67 \%$ of the total reads. At the genus level (Figure 3), Vibrio $(3.5 \% \sim 71.1 \%)$, Mycoplasma $(2.6 \% \sim 55.4 \%)$ and 


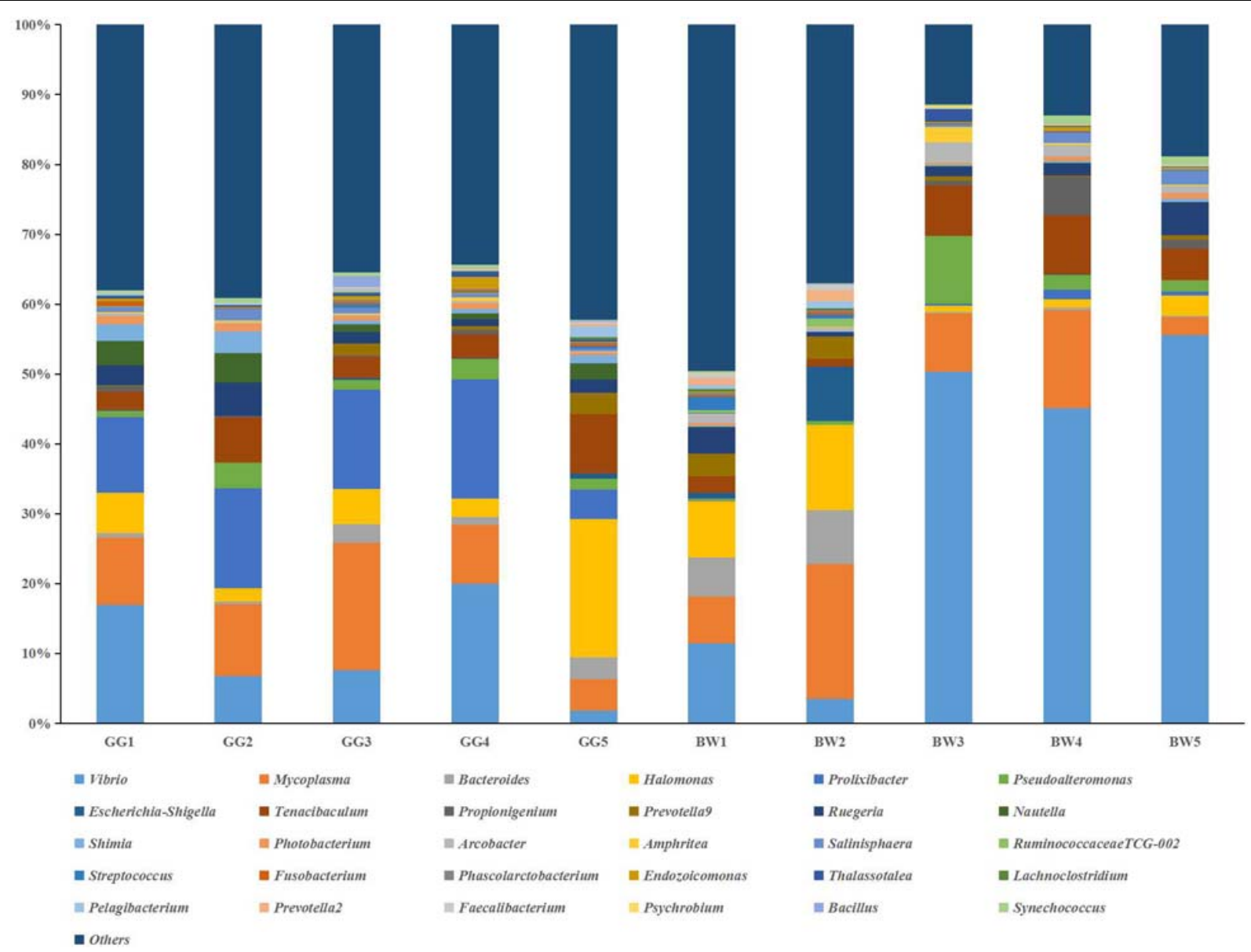

FIGURE 3 | Relative abundance of the genus level in guts of noble scallops. Sample from GG1 to GG5 was collected from GG, and sample from BW1 to BW5 was collected from BW, respectively. Groups within the same bacterial genus are indicated by different shades of the same color.
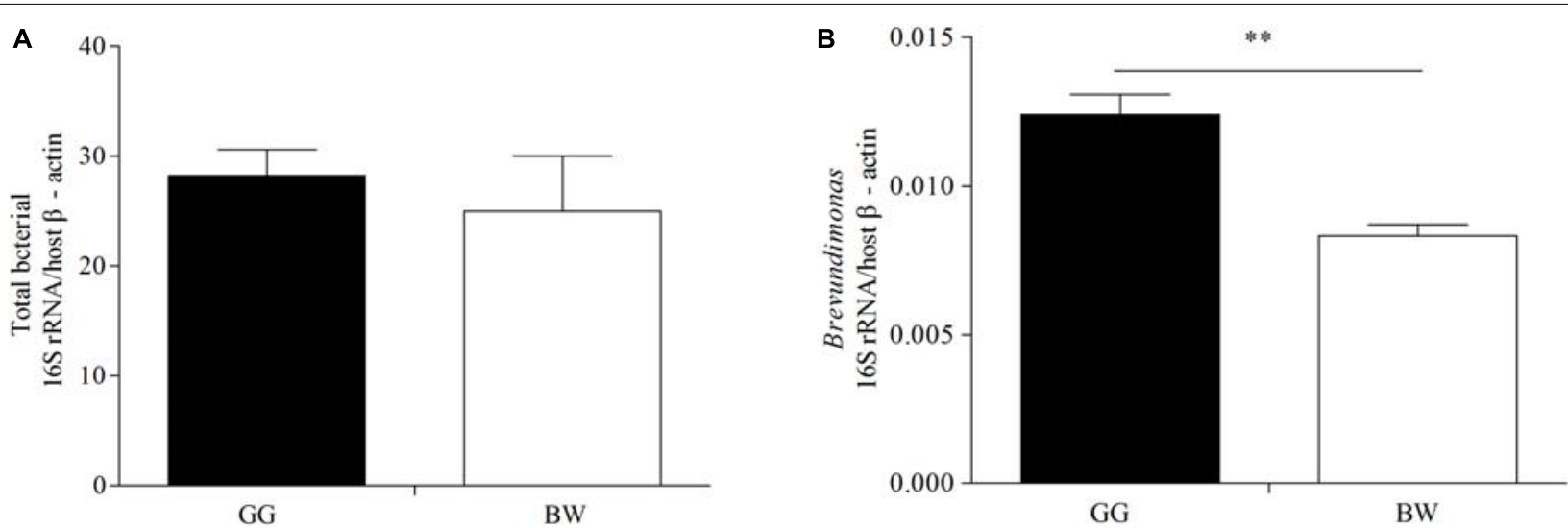

FIGURE 4 | Quantification the 16S rRNA gene of total bacteria (A) and Brevundimonas (B) in gut samples from two groups (GG and BW). The levels of total bacterial 16S rRNA gene and Brevundimonas 16S rRNA gene were normalized by the expression of the host $\beta$-actin gene. The values are expressed as means \pm SD $(n=5)$. The asterisks $\left.{ }^{* *} P<0.01\right)$ indicate significant differences in two groups.

Bacteroides $(0.05 \% \sim 20.1 \%)$ were dominant in all 10 libraries. GG had significantly lower relative abundance of Vibrio (average 12.1\%) compared with BW (average 30.7\%)
$(P<0.05)$. However, there was no significant difference in the abundance of the gut bacterial 16S rRNA gene between GG and BW (Figure 4A). 


\section{Comparison of Bacterial Community Structure Between Golden and Brown Scallops}

The composition of bacterial community measured by the weighted UniFrac PCoA analysis is illustrated in Figure 5. The GG samples clustered together, whereas the BW samples were more variable and dispersed. In addition, the ANOSIM test results $(R=0.829, P=0.024)$ indicated significant differences between the bacterial communities of GG and BW.

\section{Comparison of Biosynthetic Capabilities of Gut Microbiota From Golden and Brown Scallops}

In order to estimate the bacteria biosynthetic abilities, PICRUSt was used to predict the gut microbiome functions. As shown in Figure 6, compared with brown scallops (BW) the gut microbiota of golden scallops (GG) contained higher abundance of functional genes including those involved in the biosynthesis of carotenoids, fatty acids, terpenoids backbone, and betalain at KEGG level $3(P<0.05)$.

\section{Isolation and Identification of Potential Carotenoids-Producing Bacteria in Gut}

A total of seven potential carotenoids-producing bacteria were isolated from the gut of golden scallops and their phylogenetic affiliation was studied by a conventional $16 \mathrm{~S}$ rRNA gene-based method. As shown in Table 2, the potential carotenoids-producing bacteria were classified into four genera (Brevundimonas, Sphingomonas, Rhodococcus, and Acinetobacter). Most isolates were obtained from LB medium, possibly due to its relatively high salt concentration $(1 \% \mathrm{NaCl})$. All the potential carotenoid-producing strains (G2, G3, G14, G17, G36, G42, G61) produced yellow, orange or red pigments, and their extracts have similar light absorbance (around $480 \mathrm{~nm}$ ) with carotenoids.

\section{Abundance of Carotenoids-Producing Bacteria Brevundimonas in the Gut of Golden and Brown Scallops}

Based on the result of $16 \mathrm{~S}$ rRNA high-throughput sequencing, we found that the abundance of the genera Brevundimonas (OTU_124 corresponding to strains G2 and G3) was significantly higher $(P<0.05)$ in the gut of GG compared with BW (Table 2). Similar results were obtained by quantitative PCR analysis, where the abundance of Brevundimonas 16S rRNA gene was significantly higher in GG compared with BW (Figure 4B). However, the abundance of other potential carotenoids-producing bacteria (Sphingomonas, Rhodococcus, and Acinetobacter) was not statistically different between two groups (Table 2).

In addition, the extracts of the isolate Brevundimonas were identified by HPLC-MS (Figure 7). The results showed that the Brevundimonas produced six types of carotenoids with peaks (1, $2,3,4,5$, and 6) recorded at different $R_{t}$. The $m / z$ of peak 6 was

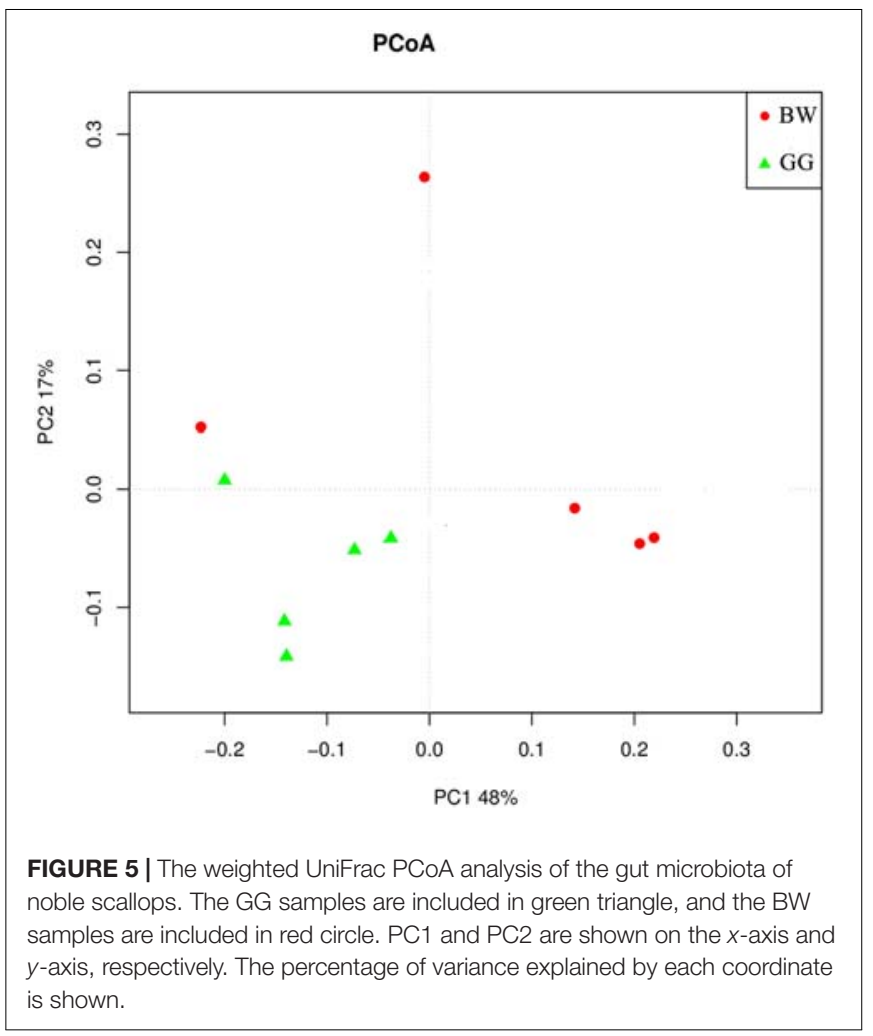

$597\left[\mathrm{M}^{+}+1\right.$ and $\left.\mathrm{M}^{+}+23\right]$, which is similar to the astaxanthin standard (Figure 7).

\section{DISCUSSION}

A broad range of studies on animal-associated bacteria communities have advanced our understanding of the interaction between animals and bacteria. Gut microbiota plays important roles in the health, physiology, and behavior of animals (Erkosar et al., 2013; Mardinoglu et al., 2015). Although gut microbiota has been extensively explored in vertebrates, gut microbiota of marine invertebrates is less understood. In the present study, we compared the TCC and gut microbiota between golden and brown scallops. The golden and brown scallops used in the present study were cultivated under the same environmental conditions (on a farm in Nan'ao Island) and fed on the same microalgae composition. Therefore, we assume that the different levels of accumulated carotenoids between golden and brown scallops were contributed to by their gut microbiota. Based on the $16 \mathrm{~S}$ rRNA gene high-throughput sequencing, GG had different bacteria communities compared with BW. Among the three major genera identified (Vibrio, Mycoplasma, and Bacteroides), only the relative abundance of Vibrio was statistically different, with the relative abundance of Vibro in the gut of GG significantly lower than that of BW. As a potential pathogenic bacterial, Vibrio might be associated with the immunity of bivalve mollusks (Pierce et al., 2016), suggesting that a high carotenoid content in the gut of GG might help lower the relative abundance of Vibrio. In addition, Mycoplasma 


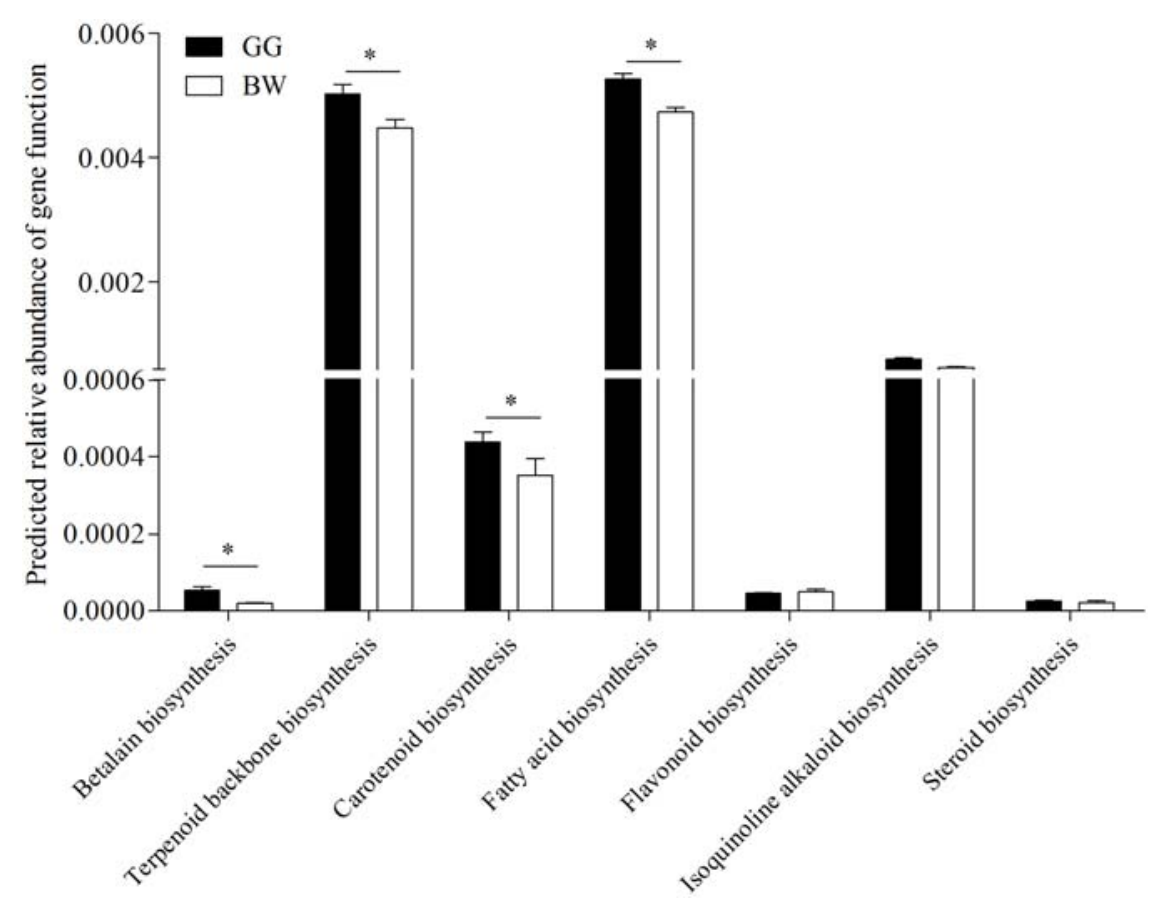

FIGURE 6 | Predicted relative abundance of partial functional genes of PICRUSt-generated functional profile of gut microbiota between golden and brown noble scallops. Significant differences in gene categories related to KEGG pathways at level 3 between two scallop groups (GG and BW). Date are shown as the mean $\pm \mathrm{SD} * P<0.05$.

TABLE 2 | Phylogenetic and physiological characteristics of the potential carotenoids-producing strains.

\begin{tabular}{|c|c|c|c|c|c|c|c|c|c|}
\hline \multirow{2}{*}{$\begin{array}{l}\text { Strains } \\
\text { number }\end{array}$} & \multirow{2}{*}{$\begin{array}{l}\text { Isolated } \\
\text { mediaA }^{A}\end{array}$} & \multirow{2}{*}{$\begin{array}{l}\text { Closest GeneBank relative } \\
\text { (accession number) }\end{array}$} & \multirow{2}{*}{$\begin{array}{c}\text { Similarity } \\
\text { (\%) }\end{array}$} & \multirow{2}{*}{$\begin{array}{c}\text { Query } \\
\text { length (bp) }\end{array}$} & \multirow[t]{2}{*}{ Colony ${ }^{B}$} & \multirow{2}{*}{$\begin{array}{l}\text { Related } \\
\text { OTUs }^{C}\end{array}$} & \multicolumn{2}{|c|}{ Relative abundance $^{\mathrm{D}}$} & \multirow{2}{*}{$\begin{array}{c}\text { Carotenoid } \\
\text { spectrum }(\lambda \max n m)\end{array}$} \\
\hline & & & & & & & GG & BW & \\
\hline G2 & $L$ & $\begin{array}{l}\text { Brevundimonas vesicularis } \\
\text { (NZ_CP022048.2) }\end{array}$ & 99 & 1392 & $\mathrm{R} / \mathrm{s} / \mathrm{g}$ & OTU_124 & $0.096 \pm 0.012^{a}$ & $0.02 \pm 0.009^{b}$ & 476 \\
\hline G3 & $\mathrm{L}$ & $\begin{array}{l}\text { Brevundimonas subvibrioides } \\
\text { (NC_014375.1) }\end{array}$ & 97 & 1395 & $\mathrm{R} / \mathrm{g} / \mathrm{s} / \mathrm{S}$ & OTU_124 & $0.096 \pm 0.012^{a}$ & $0.02 \pm 0.009^{b}$ & 476,484 \\
\hline G14 & $L$ & $\begin{array}{l}\text { Sphingomonas melonis TY } \\
\text { (NZ_CP017578.1) }\end{array}$ & 96 & 1386 & Y/S & OTU_52 & $0.22 \pm 0.14^{a}$ & $0.17 \pm 0.17^{a}$ & 442 \\
\hline G17 & L/N & $\begin{array}{l}\text { Sphingomonas paucimobilis } \\
\text { NBRC } 13935 \\
\text { (NZ_BBJS01000072.1) }\end{array}$ & 99 & 1401 & $\mathrm{Y} / \mathrm{S} / \mathrm{L}$ & OTU_52 & $0.22 \pm 0.14^{a}$ & $0.17 \pm 0.17^{a}$ & 472 \\
\hline G36 & L/N & $\begin{array}{l}\text { Rhodococcus erythropolis } \\
\text { CCM2595 (NC_022115.1) }\end{array}$ & 99 & 1411 & $\mathrm{R} / \mathrm{L}$ & OTU_1020 & $0.01 \pm 0.023^{a}$ & $0.018 \pm 0.031^{a}$ & 449,492 \\
\hline G42 & L/N & $\begin{array}{l}\text { Rhodococcus erythropolis } \\
\text { CCM2595 (NC_022115.1) }\end{array}$ & 98 & 1427 & $\mathrm{R} / \mathrm{S}$ & OTU_1020 & $0.01 \pm 0.023^{a}$ & $0.018 \pm 0.031^{a}$ & 452 \\
\hline G61 & $\mathrm{N} / \mathrm{M}$ & $\begin{array}{l}\text { Acinetobacter pittii PHEA-2 } \\
\text { (NC_016603.1) }\end{array}$ & 99 & 1442 & $\mathrm{O} / \mathrm{L}$ & OTU_30 & $0.43 \pm 0.11^{a}$ & $0.41 \pm 0.21^{a}$ & 478 \\
\hline
\end{tabular}

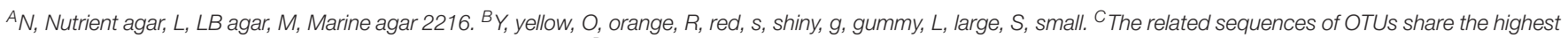

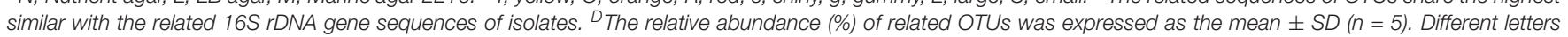

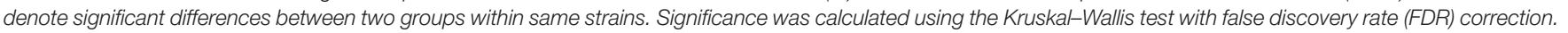

and Bacteroides were the dominant bacteria in gut of noble scallops, suggesting that these bacterial genera were well-adapted to conditions of the scallops' gut. Recent studies have shown that Bacteroides are able to digest marine carbohydrates (Sonnenburg et al., 2010; Hehemann et al., 2012). Similarly, previous studies have indicated that Mycoplasma was the dominant bacteria in the gut of aquatic animals, but their function remains unknown (Bano et al., 2007).

Our previous studies show that the adductor and mantle of golden scallops contained significantly higher carotenoids content compared with brown scallops, with these differences in carotenoids content attributed to genetic 


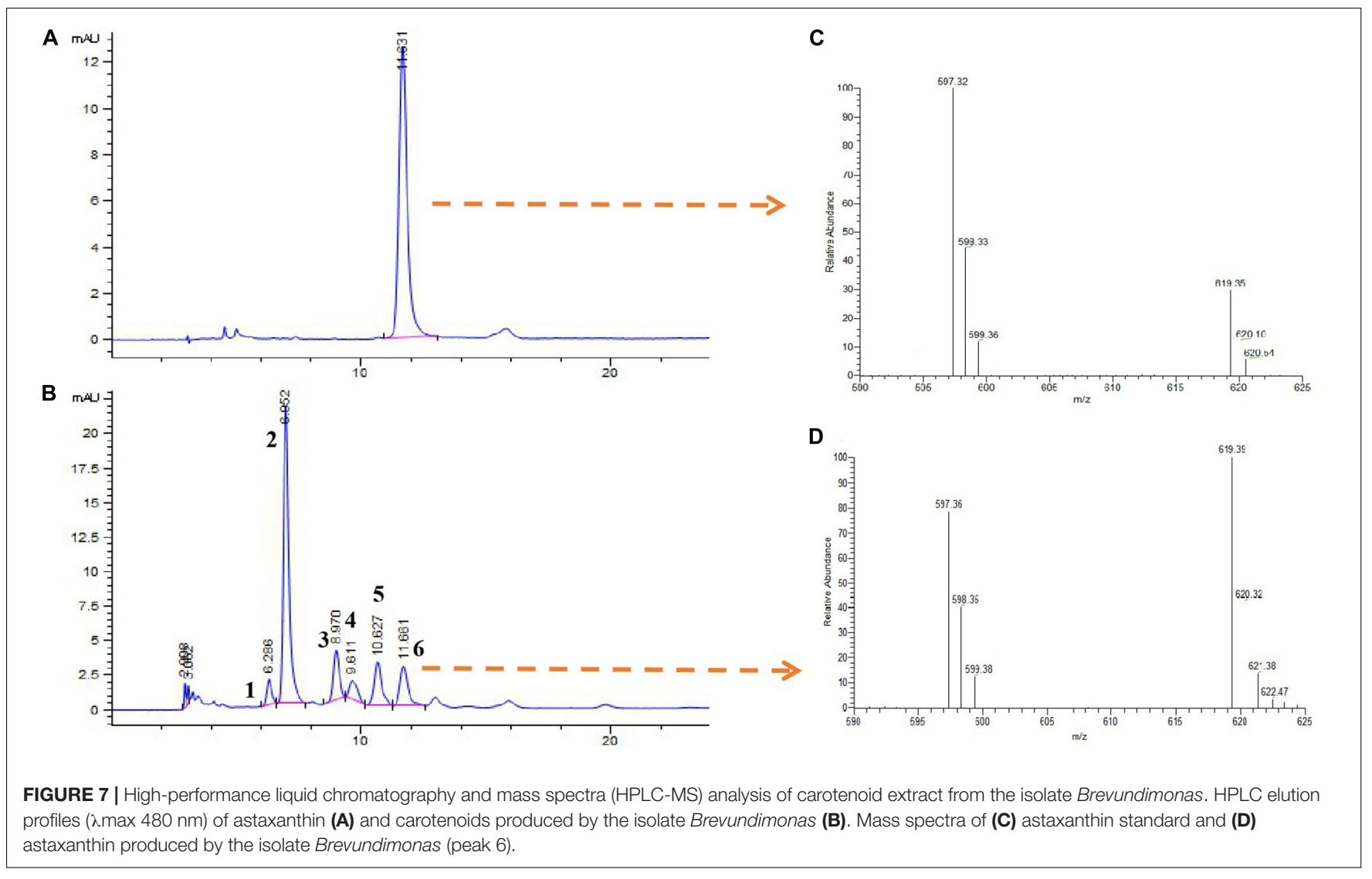

factors (Zheng et al., 2013) as well as control by carotenoid absorption-related genes such as SRB-like-3 (Liu et al., 2015). In the present study, golden scallops were found to contain significantly higher carotenoids content in their adductor, guts and hemolymph compared with brown scallops. It is believed that carotenoids in diets are absorbed by the gut and transported in hemolymph to be accumulated in other body tissues (Liu et al., 2015).

One notable and interesting observation in that current study was that some carotenoid-producing bacteria that could contribute to the accumulation of carotenoids in golden scallops were identified. Similar observations have been documented in cephalopods (Barbieri et al., 1996; Grigioni et al., 2000) and sponges (Miki et al., 1994), where gut bacteria were suggested to provide carotenoids to their host. Analysis of the potential functions of bacterial communities revealed that the gut microbiota in GG had a high abundance of functional genes that are involved in the biosynthesis of fatty acids, terpenoids backbone and carotenoids, which could partly explain the gold coloration and deposition of carotenoids in the gut of golden scallops. This observation is consistent with Zheng et al. (2012a), who reported a strong positive correlation between TCC and total lipid content in tissues of noble scallops. Moreover, the terpenoids backbone is an essential precursor for the biosynthesis of carotenoids (Römer and Fraser, 2005; Yonekura and Nagao, 2010). The 16S rRNA high-throughput sequencing results also revealed 11 bacteria genera that are potential carotenoid producers (Supplementary Table S1), although these bacteria constituted a small group $(<1 \%)$. Thus, in order to verify the occurrence of carotenoid-producing bacteria in the gut of noble scallops, a culture method was used. Indeed, a number of potential carotenoid-producing bacteria in the gut of GG were found, with phylogenetic analysis revealing that these bacteria belong to the genera Brevundimonas, Sphingomonas, Rhodococcus, and Acinetobacter. A high proportion of the isolates comprised of Brevundimonas and Sphingomonas, which are well-known in carotenoid production (Asker et al., 2018). Similarly, Rhodococcus are a class of photosynthetic bacteria known to produce carotenoids such as Canthaxanthin (Hannibal et al., 2000). Although there is no information on carotenoid production by Acinetobacter, our results showed that some strains that belong to Acinetobacter exhibit orange pigmentation that has similar light absorbance with carotenoids (Table 2).

Intriguingly, our results revealed that the abundance of the carotenoid-producing bacteria Brevundimonas was significantly higher in the gut of GG compared with BW, although Brevundimonas only accounted for $0.03-0.05 \%$ of the total bacteria community in all tested individuals. These observations suggest that Brevundimonas are resident bacteria in the gut of noble scallops. To confirm the carotenoid biosynthetic ability of Brevundimonas, carotenoids were extracted from this isolate and identified using HPLC-MS. The 
data revealed that Brevundimonas could produce astaxanthin and other unknown carotenoids. Marine Brevundimonas have been reported to produce many carotenoids such as xanthophyll (Nishida et al., 2005), astaxanthin, adonixanthin, and other ketocarotenoids (Asker et al., 2018). Other studies including Teramoto et al. (2003), Stafsnes et al. (2010), and Asker et al. (2018) have all reported that marine bacteria are important sources of natural carotenoids. Therefore, we strongly believe that the high carotenoid content in the gut of golden scallops might be related to the carotenoid-producing bacteria Brevundimonas. Our results are also backed by similar previous studies, where isolated Brevundimonas sp. SD-212 was reported to produce several carotenoid compounds, including 2-hydroxyastaxanthin, 2-hydroxyadonixanthin, erythroxanthin, 2,2'-dihydroxyastaxanthin, 2,2'-dihydroxyadonixanthin, adonix anthin, and astaxanthin (Yokoyama et al., 1996). Thus, it seems that the other unknown carotenoids produced by isolate Brevundimonas in our current study could be hydroxylated derivatives of astaxanthin such as 2-hydroxyastaxanthin and 2,2' dihydroxyastaxanthin. After all, astaxanthin is widely distributed in tissues of marine animals, including marine scallops (Suhnel et al., 2009). However, since the present study was not designed to assess the role of carotenoid producing bacteria in carotenoid accumulation in scallops, we are only able to speculate that some of the carotenoids absorbed by noble scallops could possibly originate from gut bacteria. Future studies would explore if some of the carotenoids absorbed by bivalves are from their gut bacteria.

\section{CONCLUSION}

In conclusion, the gut of golden noble scallops contained significantly higher TCC compared with brown scallops. The gut of golden scallops has a different bacteria community and has a higher proportion of carotenoid-producing bacteria Brevundimonas compared with brown scallops. These observations are first observed in mollusks, and therefore provide

\section{REFERENCES}

Adams, A. S., Jordan, M. S., Adams, S. M., Suen, G., Goodwin, L. A., Davenport, K. W., et al. (2011). Cellulose-degrading bacteria associated with the invasive wood wasp Sirex noctilio. ISME J. 5, 1323-1331. doi: 10.1038/ismej. 2011.14

Altincicek, B., Kovacs, J. L., and Gerardo, N. M. (2012). Horizontally transferred fungal carotenoid genes in the two-spotted spider mite Tetranychus urticae. Biol. Lett. 8, 253-257. doi: 10.1098/rsbl.2011.0704

Asker, D., Awad, T. S., Beppu, T., and Ueda, K. (2018). Screening and profiling of natural ketocarotenoids from environmental aquatic bacterial isolates. Food. Chem. 253, 247-254. doi: 10.1016/j.foodchem.2018.01.066

Asker, D., Beppu, T., and Ueda, K. (2007). Unique diversity of carotenoidproducing bacteria isolated from misasa, a radioactive site in japan. Appl. Microbiol. Biotechnol. 77, 383-392. doi: 10.1007/s00253-007-1157-8

Bano, N., Smith, A., Bennett, W., Vasquez, L., and Hollibaugh, J. T. (2007). Dominance of Mycoplasma in the guts of the long-jawed mudsucker, Gillichthys mirabilis, from five California salt marshes. Environ. Microbiol. 9, 2636-2641. doi: $10.1111 /$ j.1462-2920.2007.01381.x valuable information for future studies on exploring carotenoids accumulation in marine invertebrates.

\section{DATA AVAILABILITY STATEMENT}

Sequence data has been deposited at NCBI under BioProject number PRJNA574069.

\section{AUTHOR CONTRIBUTIONS}

HL, HM, SL, and HuZ conceived and designed the experiments. KT, XZ, HL, and HuZ wrote the manuscript. HoZ, DC, and YT collected and prepared the samples.

\section{FUNDING}

This work was financially supported by the National Natural Science Foundation of China (31872563 and 41706185), Science and Technology Innovation Committee of Shenzhen (JCYJ20180305163524811), China Modern Agro-industry Technology Research System (CARS-49), and Department of Education of Guangdong Province (2017KCXTD014).

\section{ACKNOWLEDGMENTS}

We are very grateful to Dr. Jude Juventus Aweya (Department of Biology, Shantou University) for his careful revision and many constructive comments.

\section{SUPPLEMENTARY MATERIAL}

The Supplementary Material for this article can be found online at: https://www.frontiersin.org/articles/10.3389/fmicb. 2020.00036/full\#supplementary-material

Barbieri, E., Gulledge, J., Moser, D. P., and Chien, C. C. (1996). New evidence for bacterial diversity in accessory nidamental gland of the squid (Lologo forbesi). Biol. Bull. 191, 316-317. doi: 10.1086/bblv191n $2 \mathrm{p} 316$

Borisovets, E. E., Zadorozhny, P. A., Kalinina, M. V., and Lepskaya, N. V. (2002). Changes of major carotenoids in gonads of sea urchins (Strongylocentrotus intermedius and S. nudus) at maturation. Comp. Biochem. Phys. B 132B, 779790. doi: 10.1016/s1096-4959(02)00099-94

Caporaso, J. G., Lauber, C. L., Walters, W. A., Berg-Lyons, D., Lozupone, C. A., Turnbaugh, P. J., et al. (2011). Global patterns of $16 \mathrm{~S}$ rRNA diversity at a depth of millions of sequences per sample. Proc. Natl. Acad. Sci. U.S.A. 108, 4516-4522. doi: 10.1073/pnas.1000080107

Carmody, R. N., and Turnbaugh, P. J. (2014). Host-microbial interactions in the metabolism of therapeutic and diet-derived xenobiotics. J. Clin. Invest. 124, 4173-4181. doi: 10.1172/JCI72335

Cobbs, C., Heath, J., Stireman, I. I. I. J. O., and Abbot, P. (2013). Carotenoids in unexpected places: gall midges, lateral gene transfer, and carotenoid biosynthesis in animals. Mol. Phylogenet. Evol. 68, 221-228. doi: 10.1016/j. ympev.2013.03.012 
Dabek, M., McCrae, S. I., Stevens, V. J., Duncan, S. H., and Louis, P. (2008). Distribution of beta-glucosidase and beta-glucuronidase activity and of betaglucuronidase gene gus in human colonic bacteria. FEMS Microbiol. Ecol. 66, 487-495. doi: 10.1111/j.1574-6941.2008.00520.x

Erkosar, B., Storelli, G., Defaye, A., and Leulier, F. (2013). Host-intestinal microbiota mutualism: "learning on the fly". Cell Host Microbe. 13, 8-14. doi: 10.1016/j.chom.2012.12.004

Givens, C. E., Burnett, K. G., Burnett, L. E., and Hollibough, J. (2013). Microbial communities of the carapace, gut, and hemolymph of the Atlantic blue crab, Callinectes sapidus. Mar. Biol. 160, 2841-2851. doi: 10.1007/s00227-013-22752278

Grigioni, S., Boucher-Rodoni, R., Demarta, A., Tonolla, M., and Peduzzi, R. (2000). Phylogenetic characterisation of bacterial symbionts in the accessory nidamental glands of the sepioid Sepia officinalis, (Cephalopoda: Decapoda). Mar. Biol. 136, 217-222. doi: 10.1007/s002270050679

Guo, X., Xia, X., and Tang, R. (2008). Real-time PCR quantification of the predominant bacterial divisions in the distal gut of Meishan and Landrace pigs. Anaerobe 14, 224-228. doi: 10.1016/j.anaerobe.2008.04.001

Hannibal, L., Lorquin, J., D’Ortoli, N. A., Garcia, N., Chaintreuil, C., MassonBoivin, C., et al. (2000). Isolation and characterization of canthaxanthin biosynthesis genes from the photosynthetic bacterium Bradyrhizobiumsp. Strain ORS278. J. Bacteriol. 182, 3850-3853. doi: 10.1128/jb.182.13.3850-3853. 2000

Hehemann, J. H., Kelly, A. G., Pudlo, N. A., Martens, E. C., and Boraston, A. B. (2012). Bacteria of the human gut microbiome catabolize red seaweed glycans with carbohydrate-active enzyme updates from extrinsic microbes. Proc. Natl. Acad. Sci. U.S.A. 109, 19786-19791. doi: 10.1073/pnas.1211002109

Ikeda, M., Hosotani, T., Kurimoto, K., Mori, T., Ueda, T., Kotake, Y., et al. (1979). The differences of the metabolism related to vitamin B6-dependent enzymes among vitamin B6-deficient germ-free and conventional rats. J. Nutr. Sci. Vitaminol. 25, 131-139. doi: 10.3177/jnsv.25.131

Immerseel, V. F., Ducatelle, R., Vos, M. D., Boon, N., Wiele, T. V. D., Verbeke, K., et al. (2010). Butyric acid-producing anaerobic bacteria as a novel probiotic treatment approach for inflammatory bowel disease. J. Med. Microbiol. 59, 141-143. doi: 10.1099/jmm.0.017541-0

Kantha, S. S. (1989). Carotenoids of edible molluscs: a review. J. Food. Biochem. 13, 429-442. doi: 10.1111/j.1745-4514.1989.tb00410.x

Lane, D. J. (1991). "16S/23S rRNA sequencing," in Nucleic Acid Techniques in Bacterial Systematics, eds E. Stackebrandt, and M. Goodfellow, (Chichester: John Wiley and Sons), 115-175.

Langille, M. G., Zaneveld, J., Caporaso, J. G., McDonald, D., Knights, D., Reyes, J. A., et al. (2013). Predictive functional profiling of microbial communities using 16S rRNA marker gene sequences. Nat. Biotechnol. 31:814. doi: 10.1038/ nbt. 2676

Liu, H., Zheng, H., Zhang, H., Deng, L., Liu, W., Wang, S., et al. (2015). A de novo transcriptome of the noble scallop, Chlamys nobilis, focusing on mining transcripts for carotenoid-based coloration. BMC Genomics. 16:44. doi: 10. 1186/s12864-015-1241-x

Lozupone, C. A., Stombaugh, J. I., Gordon, J. I., Jansson, J. K., and Knight, R. (2012). Diversity, stability and resilience of the human gut microbiota. Nature 489, 220-230. doi: 10.1038/nature 11550

Maoka, T. (2009). Recent progress in structural studies of carotenoids in animals and plants. Arch. Biochem. Biophys. 483, 191-195. doi: 10.1016/j.abb.2008.10. 019

Maoka, T. (2011). Carotenoids in marine animals. Mar. Drugs 9, 278-293. doi: 10.3390/md9020278

Mardinoglu, A., Shoaie, S., Bergentall, M., Ghaffari, P., Zhang, C., Larsson, E., et al. (2015). The gut microbiota modulates host amino acid and glutathione metabolism in mice. Mol. Syst. Biol. 11, 834. doi: 10.15252/msb.20156487

Matsuno, T. (2001). Aquatic animal carotenoids. Fish. Sci. 67, 771-783. doi: 10. 1046/j.1444-2906.2001.00323.x

Matsuno, T., and Hirao, S. (1989). “Marine carotenoids," in Marine Biogenic Lipids, Fats, and Oils, ed. R. G. Ackman (Boca Raton, FL: CRC Press), 251-388.

Miki, W., Otaki, N., Yokoyama, A., Izumida, H., and Shimidzu, N. (1994). Okadaxanthin, a novel C50-carotenoid from a bacterium, Pseudomonas sp. KK10206C associated with marine sponge, Halichondria okadai. Cell Mol. Life Sci. 50, 684-686. doi: 10.1007/BF01952874
Moran, N. A., and Jarvik, T. (2010). Lateral transfer of genes from fungi underlies carotenoid production in aphids. Science 328, 624-627. doi: 10.1126/science. 1187113

Negro, J. J., and Garrido-Fernèndez, J. (2000). Astaxanthin is the major carotenoid in tissues of white storks (Ciconia ciconia) feeding on introduced crayfish (Procambarus clarkii). Comp. Biochem. Phys. B 126, 347-352. doi: 10.1016/ s0305-0491(00)00180-182

Nishida, Y., Adachi, K., Kasai, H., Shizuri, Y., Shindo, K., Sawabe, A., et al. (2005). Elucidation of a carotenoid biosynthesis gene cluster encoding a novel enzyme, $2,2^{\prime}$ - 3 -hydroxylase, from Brevundimonas sp. strain SD212 and combinatorial biosynthesis of new or rare xanthophylls. Appl. Environ. Microb. 71, 4286-4296. doi: 10.1128/AEM.71.8.4286-4296.2005

Nováková, E., and Moran, N. A. (2011). Diversification of genes for carotenoid biosynthesis in aphids following an ancient transfer from a fungus. Mol. Biol. Evol. 29, 313-323. doi: 10.1093/molbev/msr206

Pierce, M. L., Ward, J. E., Holohan, B. A., Zhao, X. W., and Hicks, R. E. (2016). The influence of site and season on the gut and pallial fluid microbial communities of the eastern oyster, Crassostrea virginica, (Bivalvia, Ostreidae): communitylevel physiological profiling and genetic structure. Hydrobiologia 765, 97-113. doi: 10.1007/s10750-015-2405-z

Poulsen, M., Hu, H., Li, C., Chen, Z., Xu, L., Otani, S., et al. (2014). Complementary symbiont contributions to plant decomposition in a fungus-farming termite. Proc. Natl. Acad. Sci. U.S.A. 111, 14500-14505. doi: 10.1073/pnas.1319718111

Ramotar, K., Conly, J. M., Chubb, H., and Louie, T. J. (1984). Production of menaquinones by intestinal anaerobes. J. Infect. Dis. 150, 213-218. doi: 10.1093/ infdis/150.2.213

Richardson, C., Hill, M., Marks, C., Janecky, L. R., and Hill, A. (2012). Experimental manipulation of sponge/bacterial symbiont community composition with antibiotics: sponge cell aggregates as a unique tool to study animal/microorganism symbiosis. FEMS Microbiol. Ecol. 81, 407-418. doi: 10.1111/j.1574-6941.2012.01365.x

Römer, S., and Fraser, P. D. (2005). Recent advances in carotenoid biosynthesis, regulation and manipulation. Chin. Agric. Sci. Bull. 221, 305-308. doi: 10.1007/ s00425-005-1533-1535

Salem, H., Bauer, E., Kirsch, R., Berasategui, A., Cripps, M. G., Weiss, B., et al. (2017). Drastic genome reduction in an herbivore's pectinolytic symbiont. Cell 171, 1-12. doi: 10.1016/j.cell.2017.10.029

Schloss, P. D., Westcott, S. L., Ryabin, T., Hall, J. R., Hartmann, M., Hollister, E. B., et al. (2009). Introducing mothur: opensource, platform-independent, community-supported software for describing and comparing microbial communities. Appl. Environ. Microbiol. 75, 7537-7541. doi: 10.1128/AEM. 01541- 1549

Schmitt, S., Tsai, P., Bell, J., Fromont, J., Ilan, M., Lindquist, N., et al. (2012). Assessing the complex sponge microbiota: core, variable and species-specific bacterial communities in marine sponges. ISME J. 6, 564-576. doi: 10.1038/ ismej.2011.116

Sloan, D. B., and Moran, N. A. (2011). Endosymbiotic bacteria as a source of carotenoids in whiteflies. Biol. Lett. 8, 986-989. doi: 10.1098/rsbl.2012.0664

Sommer, F., and Bäckhed, F. (2013). The gut microbiota-masters of host development and physiology. Nat. Rev. Microbiol. 11, 227-238. doi: 10.1038/ nrmicro2974

Sonnenburg, E. D., Zheng, H., Joglekar, P., Higginbottom, S., Firbank, S. J., Bolam, D. N., et al. (2010). Specificity of polysaccharide use in intestinal Bacteroides species determines diet-induced microbiota alterations. Cell 141, 1241-1252. doi: 10.1016/j.cell.2010.05.005

Sonnenburg, J. L., and Bäckhed, F. (2016). Diet-microbiota interactions as moderators of human metabolism. Nature 535, 56-64. doi: 10.1038/ nature 18846

Stafsnes, M. H., Josefsen, K. D., Kildahlandersen, G., Valla, S., Ellingsen, T. E., and Bruheim, P. (2010). Isolation and characterization of marine pigmented bacteria from Norwegian coastal waters and screening for carotenoids with UVA-blue light absorbing properties. J. Microbiol. 48, 16-23. doi: 10.1007/ s12275-009-0118-116

Suhnel, S., Lagreze, F., Ferreira, J., Campestrini, L. H., and Maraschin, M. (2009). Carotenoid extraction from the gonad of the scallop Nodipecten nodosus (Linnaeus, 1758) (Bivalvia: Pectinidae). Braz. J. Biol. 69, 209-215. doi: 10.1590/ s1519-69842009000100028 
Tabunoki, H., Higurashi, S., Ninagi, O., Fujii, H., Banno, Y., Nozaki, M., et al. (2004). A carotenoid-binding protein (CBP) plays a crucial role in cocoon pigmentation of silkworm (Bombyx mori) larvae. FEBS Lett. 567, 175-178. doi: 10.1016/j.febslet.2004.04.067

Tanumihardjo, S. A. (2013). Carotenoids and human health. Nutr. Health 55, 77-78. doi: 10.1007/978-1-62703-203-202

Teramoto, M., Takaichi, S., Inomata, Y., Ikenaga, H., and Misawa, N. (2003). Structural and functional analysis of a lycopene beta-monocyclase gene isolated from a unique marine bacterium that produces myxol. FEBS Lett. 545, 120-126. doi: 10.1016/S0014-5793(03)00513-511

Trabal, F. N., Mazónsuástegui, J. M., Vázquezjuárez, R., AscencioValle, F., and Romero, J. (2014). Changes in the composition and diversity of the bacterial microbiota associated with oysters (Crassostrea corteziensis, Crassostrea gigas and Crassostrea sikamea) during commercial production. FEMS Microbiol. Ecol. 88, 69-83. doi: 10.1111/1574-6941.12270

Umbers, K. D. L., Silla, A. J., Bailey, J. A., Shaw, A. K., and Byrne, P. (2016). Dietary carotenoids change the colour of Southern corroboree frogs. Biol. J. Linn. Soc. 119, 436-444. doi: 10.1111/bij.12818

Wang, Q., Garrity, G. M., Tiedje, J. M., and Cole, J. R. (2007). Naïve Bayesian classifier for rapid assignment of rRNA sequences into the new bacterial taxonomy. Appl. Environ. Microbiol. 73, 5261-5267. doi: 10.1128/aem.000 62-67

Wang, Y. J., Chien, Y. H., and Pan, C. H. (2006). Effects of dietary supplementation of carotenoids on survival, growth, pigmentation, and antioxidant capacity of characins, Hyphessobrycon callistus. Aquaculture 261, 641-648. doi: 10.1016/j. aquaculture.2006.08.040

Weaver, R. J., Santos, E. S. A., Tucker, A. M., Wilson, A. E., and Hill, G. E. (2018). Carotenoid metabolism strengthens the link between feather coloration and individual quality. Nat. Commun. 9:73. doi: 10.1038/s41467-017-02 649-z

White, J. R., Nagarajan, N., and Pop, M. (2009). Statistical methods for detecting differentially abundant features in clinical metagenomic samples. PLoS Comput. Biol. 2009:e1000352. doi: 10.1371/journal.pcbi.1000352

Yanar, Y., Çelik, M., and Yanar, M. (2004). Seasonal changes in total carotenoid contents of wild marine shrimps (Penaeus semisulcatus, and Metapenaeus monoceros) inhabiting the eastern Mediterranean. Food Chem. 88, 267-269. doi: 10.1016/j.foodchem.2004.01.037
Yokoyama, A., Miki, W., Izumida, H., and Shizuri, Y. (1996). New trihydroxy-ketocarotenoids isolated from an astaxanthin-producing marine bacterium. Biosci. Biotech. Bioch. 60, 200-203. doi: 10.1271/bbb.60.200

Yolton, D. P., and Savage, D. C. (1976). Influence of certain indigenous gastrointestinal microorganisms on duodenal alkaline phosphatase in mice. Appl. Environ. Microbiol. 31, 880-888. doi: 10.1007/BF0041 0184

Yonekura, L., and Nagao, A. (2010). Intestinal absorption of dietary carotenoids. Mol. Nutr. Food Res. 51, 107-115. doi: 10.1002/mnfr.20060 0145

Zheng, H., Liu, H., Liu, W., Sun, Z., and Zhang, Q. (2012a). Changes of total carotenoid and lipid content in scallop tissues of Chlamys nobilis, (Bivalve: Pectinidae) during gonad maturation. Aquaculture 342-343, 7-12. doi: 10. 1016/j.aquaculture.2012.01.037

Zheng, H., Liu, H., Zhang, T., Wang, S., Sun, Z., Liu, W., et al. (2010). Total carotenoid differences in scallop tissues of Chlamys nobilis (Bivalve: Pectinidae) with regard to gender and shell colour. Food Chem. 122, 1164-1167. doi: 10. 1016/j.foodchem.2010.03.109

Zheng, H., Zhang, Q., Liu, H., Liu, W., Sun, Z., Li, S., et al. (2012b). Cloning and expression of vitellogenin (vg) gene and its correlations with total carotenoids content and total antioxidant capacity in noble scallop Chlamys nobilis (bivalve: pectinidae). Aquaculture 36, 46-53. doi: 10.1016/j.aquaculture.2012.08.031

Zheng, H., Zhang, T., Sun, Z., Liu, W., and Liu, H. (2013). Inheritance of shell colours in the noble scallop Chlamys nobilis, (Bivalve: Pectinidae). Aquacult. Res. 44, 1229-1235. doi: 10.1111/j.1365-2109.2012.03124.x

Conflict of Interest: The authors declare that the research was conducted in the absence of any commercial or financial relationships that could be construed as a potential conflict of interest.

Copyright @ 2020 Liu, Tan, Zhang, Zhang, Cheng, Ting, Li, Ma and Zheng. This is an open-access article distributed under the terms of the Creative Commons Attribution License (CC BY). The use, distribution or reproduction in other forums is permitted, provided the original author(s) and the copyright owner(s) are credited and that the original publication in this journal is cited, in accordance with accepted academic practice. No use, distribution or reproduction is permitted which does not comply with these terms. 